\title{
Timothée Picard, Portrait de l'artiste en dilettante wagnérien
}

Ida Merello

\section{OpenEdition}

Journals

\section{Edizione digitale}

URL: http://journals.openedition.org/studifrancesi/33508

DOI: 10.4000/studifrancesi.33508

ISSN: 2421-5856

Editore

Rosenberg \& Sellier

\section{Edizione cartacea}

Data di pubblicazione: 1 décembre 2005

Paginazione: 668-669

ISSN: 0039-2944

\section{Notizia bibliografica digitale}

Ida Merello, «Timothée Picard, Portrait de l'artiste en dilettante wagnérien», Studi Francesi [Online], 147 (XLX | III) | 2005, online dal 30 novembre 2015, consultato il 20 avril 2021. URL: http:// journals.openedition.org/studifrancesi/33508; DOI: https://doi.org/10.4000/studifrancesi.33508

Questo documento è stato generato automaticamente il 20 avril 2021.

\section{(c) $(1) \odot$}

Studi Francesi è distribuita con Licenza Creative Commons Attribuzione - Non commerciale - Non opere derivate 4.0 Internazionale. 


\title{
Timothée Picard, Portrait de l'artiste en dilettante wagnérien
}

\author{
Ida Merello
}

\section{NOTIZIA}

TIMOTHÉE PICARD, Portrait de l'artiste en dilettante wagnérien, Histoires littéraires», juill.août-sept. 2004, n 19, pp. 115-140.

1 L'A. vede svilupparsi il wagnerismo letterario attraverso l'emergenza di figure costanti, quali quella del dilettante wagneriano, del cenacolo wagneriano, del piccolo-borghese wagneriano o del neo-nazi wagneriano, che permettono di seguire la storia della recezione del compositore e dei ruoli che essa ha svolto, dall'avanguardismo elitario alla sua maggiore diffusione sociale, e infine al suo indebolimento e al suo assorbimento come fenomeno socioculturale -a parte l'interesse ancora accordato da parte di qualche personalità isolata (Julien Gracq, Robbe-Grillet). Per l'A. la figura del dilettante ricopre il massimo interesse, in quanto ritiene che la sua frequente rappresentazione negativa dipenda dal fatto che chi entra in contatto con Wagner si sente vittima di una povertà creatrice in confronto della presunta perfezione del Maestro. L'A. intende dimostrare come il passaggio da una definizione tragica a una comica di tale figura stia a rappresentare una presa di coscienza dell'impasse da parte degli scrittori. Un trattamento tragico della figura del dilettante è propria, tra gli altri, di A rebours di Huysmans 1884 (per quanto in maniera secondaria), del Trionfo della morte, $1894 \mathrm{di}$ Gabriele d'Annunzio, di Le Chercheur de tares 1898, di Catulle Mendès, là dove i protagonisti soffrono di un'impotenza generale e, soprattutto, creatrice. L'A. spazia poi sulla letteratura europea del XX secolo, aprendosi alla produzione tedesca, austriaca e italiana, mostrando la presenza e l'evoluzione comica dello stereotipo, fino al suo indebolimento. 